\title{
An Evaluation of Residents' Quality of Life through Neighborhood Satisfaction in Malaysia
}

\author{
Sepideh Sedaghatnia (Corresponding author) \\ Dept. of Architecture, Universiti Teknologi Malaysia \\ PO Box 81300, Skudai, Johor, Malaysia \\ Tel: 60-127-584-349 E-mail: sepideh_ft10@yahoo.com \\ Hasanuddin Lamit \\ Dept. of Landscape Architecture, Universiti Teknologi Malaysia \\ PO Box 81300, Skudai, Johor, Malaysia \\ Tel: 60-166-912-818Ｅ-mail: inadean@gmail.com \\ Amir Ghahramanpouri \\ Dept. of Architecture, Universiti Teknologi Malaysia \\ PO Box 81300, Skudai, Johor, Malaysia \\ Tel: 60-177-887-719 E-mail: amir_ghahramanpouri@yahoo.com \\ Sapura Bt Mohamad \\ Dept. of Landscape Architecture, Universiti Teknologi Malaysia \\ PO Box 81310, Skudai, Johor, Malaysia \\ Tel: 607-553-7309Ｅ-mail: b-sapura@utm.my
}

Received: February 18, 2013 Accepted: March 7, 2013

doi:10.5296/emsd.v2i1.3254 URL: http://dx.doi.org/10.5296/emsd.v2i1.3254

\begin{abstract}
Recently, the quality of life studies have drawn the attention of environmental designers, urban planners, and policy makers, due to its usefulness in assessing the overall satisfaction of citizens with life, and monitoring public policies. Even so, the importance of the
\end{abstract}


neighborhood environment remains the most fundamental base of life. People spend the majority of their lives in the neighborhood that influences their economic and social life. Consequently, satisfaction with the neighborhood features is an imperative indicator of the neighborhood quality, which affects residents' quality of life. The aim of this study is to evaluate an urban neighborhood attributes in Kuala Lumpur city center, Malaysia. A questionnaire survey was used in this study in order to measure residents' satisfaction based on the six factors, namely social life, good condition for children, security and safety, greenery and quietness, transport, and community facilities and services. The findings of the study indicated that, the residents were extremely satisfied with their quality of life in the city center area. On the satisfaction level, neighborhood physical features particularly proximity to the facilities pertained to the most satisfied aspects, while safety was considered the least one. In conclusion, this study has an implication for the policy makers and urban planners to construct and develop sustainable neighborhoods through residents' own assessment in order to enhance their quality of life.

Keywords: Quality of life, Life satisfaction, Neighborhood, Stated and revealed preference, City center

\section{Introduction}

Cities today are facing new challenges. Rapid urbanization, over the last few decades, has brought with it a whole host of urban problems, such as the relocation of residential areas, neighborhood degradation, socioeconomic deprivation, and inequities in health which threatened the sustainability of cities and undermined the citizens' quality of life. Therefore, enhancing quality of life as the crucial aspect of urban sustainability, gained public popularity and formed a central issue in policy making and urban development of most countries (Kamp et al., 2003).

Basically, quality of life (QOL) is a broad concept which concerns with the necessary conditions for satisfaction in a given society. The literature addressing quality of life makes two implicit distinctions. (1) QOL as a measurable variable refers to both objective and subjective indicators. The objective indicators achieve through the utilization of institutional data and statistics in the country, city or neighborhood levels. While, subjective indicators obtain from the survey research conducted to gauge peoples' perceptions, evaluation or subjective well-being (Potter et al., 2012). And, (2) QOL measures satisfaction of two different concepts; individual QOL (family life, friends, partner, and oneself satisfaction), and environmental QOL (satisfaction with the city, region, community and neighborhood) (Zebardast, 2009).

Nowadays, improving quality of life takes into consideration in current planning and policy scheme of Malaysia in order to achieve urban sustainability. However, the urban population rate in Malaysia has increased quickly in terms of the fast growing economy from $25 \%$ in 1960 to $72 \%$ in 2010 . It is predicted that more than three quarter of the total population in Malaysia will resident in the urban areas by the year 2030 (Zainal et al., 2012). Therefore, excessive urban growth has led a significant pressure on local and state governments to provide planning and urban development strategies that are intended to improve the quality of 
urban services to ensure that their citizens enjoy a higher quality of life. As a result, the Malaysian Quality of Life Index (MQLI) has been developed in 2002 by the "Economic Planning Unit (EPU), Prime Minister's Department" which defined the quality of life as "encompassing personal advances, a healthy lifestyle, access and freedom to pursue knowledge, and attaining a standard of living which surpasses the fulfilment of the basic and psychological needs of the individual, to achieve a level of social well being compatible with the nation's aspirations". Being updated in 2004, the MQLI measured citizens' well-being, based on income, employment, family life, transport and communications, health, education, housing, neighborhood, social participation and public safety (Omar, 2009).

Neighborhood as the most basic urban unit is a social context within which individuals draw satisfaction and live. Many studies revealed that satisfaction with the characteristics of neighborhood affect residents' quality of life (Sirgy et al., 2000). Furthermore, researchers believed that neighborhood satisfaction is a mediator of individual well-being and a starting point in understanding quality of life. They also indicated that, there are many factors in relation to neighborhood environment that contribute to residents' satisfaction which could be defined in terms of physical and social features (Sirgy \& Cornwell, 2002).

Regarding the importance of neighborhood quality in predicting overall quality of life and neighborhood as one of the eleven components of MQLI, this paper aims to evaluate the attributes of an urban neighborhood in Kuala Lumpur city center of Malaysia that contributes to residents' quality of life through neighborhood satisfaction. Utilizing questionnaire as the main research tool, a number of neighborhood characteristics tested against peoples' preferences and satisfaction. This questionnaire was used to define how people actually perceive their neighborhood, and which characteristics encourage people to rate their quality of life high. It is hoped that through this study, much can be learned about the residents' quality of life especially for those inhibit in the neighborhood city center areas.

\section{Literature Review}

\subsection{Defining Quality of Life}

The term 'Quality of life' (QOL) is a multi-dimensional concept which is not new and involves the crucial aspects of human existence, dating far back to early Greek philosophy, like Plato and Aristotle. But, in recent years, there have been many interests and attempts to define what constitutes quality of life. More than one hundred definitions, varying between academic disciplines, schools of thought and social groups of populations have been noted in the literatures (Windsor \& Bowling, 2001). While quality of life has common meaning in these studies, there is little consent among academics pertaining to its definition (Marans, 2012). That is why studies on the QOL represent discrepancy in the definitions.

Many scholars described the concept of quality of life interchangeably with other terms, such as subjective well-being, happiness, life satisfaction, and good life (Andrews \& Withey, 1976; Shin \& Johnson, 1978; Veenhoven, 1996; Diener \& Suh, 1997; Evans, 1994) (Refer to Table 1). Commonly, in all these definitions, the quality of life defined as a term to measure citizens' satisfaction through understanding their actual needs and implementing most desired 
development in the future (Hikmat et al., 2009). In other words, quality of life emerged from the assessment of the multiple needs of the individuals, communities, cities, and countries. The degree to which each identified need is fulfilled and contributed to the subjective well-being of people is the necessity of assessing quality of life in various fields (Costanza, 2008).

Table 1. The different definitions of quality of life

\begin{tabular}{|c|c|}
\hline \multicolumn{2}{|c|}{ Definitions } \\
\hline Campbell, Converse \& & - "QOL measures the people's perceptions, evaluation and \\
\hline Rogers (1977) & satisfaction." \\
\hline Szalai (1980) & $\begin{array}{l}\text { - "Life quality refers to the degree of excellence or satisfactory } \\
\text { character of life." }\end{array}$ \\
\hline The World Health & - “An individual's perception of his/her position in life in the \\
\hline $\begin{array}{l}\text { Organization Group } \\
(1993)\end{array}$ & $\begin{array}{l}\text { context of the culture and value systems in which he/she lives } \\
\text { and in relation to his/her goals, expectations, standards and } \\
\text { concerns". }\end{array}$ \\
\hline Raphael (1996) & $\begin{array}{l}\text { - "The degree to which a person enjoys the important possibilities } \\
\text { of his/her life." }\end{array}$ \\
\hline Veenhoven (1996) & $\begin{array}{l}\text { - "Happy life expectancy = product score of life expectancy (in } \\
\text { years) and the mean happiness" }\end{array}$ \\
\hline Musschenga (1997) & $\begin{array}{l}\text { - "The good life is a combination of enjoyment: positive mental } \\
\text { states, satisfaction: evaluation of success in realizing a life-plan } \\
\text { or personal conception of the good life and excellence: the } \\
\text { virtuousness or value of a person's activity" }\end{array}$ \\
\hline Diener \& Suh (1997) & - "Life satisfaction" \\
\hline Ventegodt (2003) & $\begin{array}{l}\text { - "Quality of life means a good life. A good life is the same as } \\
\text { living a life with high quality." }\end{array}$ \\
\hline
\end{tabular}

Nevertheless, the wide range of quality of life definitions classified into three major philosophical approaches to determining it. The first approach described QOL as the characteristics of good life based on religious or philosophical norms. This approach indicated the subjective experience of people and the fulfillment of their wishes. The second approach is based on the satisfaction of preferences which involves two elements: the identification of preferences and an evaluation of the provision of condition. Lastly, the subjective well-being (SWB) of individuals uttered as the third definition of quality of life involving factors as feelings of joy, pleasure, and life satisfaction (Diener \& Suh, 1997).

\subsection{The Quality of Life Measurement}

Since the 1930's, quality of life has become a commonly used term that researchers from different fields are interested in its measurement. In this matter, social scientists initiated two scientific approaches to measuring this concept; subjective well-being (SWB) and objective indicators. The objective indicators are societal measures that demonstrate human objective conditions in a society. Their attributes are based on quantitative statistics including infant 
mortality, crime rates, literacy rates, and indices of economic production, doctors per capita and any other data that can be gathered without directly surveying the individuals' perceptions. Objectivity is the strength of these indicators which can be easily defined and quantified without depending intensely on individual perception. As a result, it is technically convenient to make comparisons of indicators across nations, regions, demographic sectors, and time (Diener \& Suh, 1997).

While, the subjective well-being (SWB) indicators refer to measuring individual's well-being through the cognitive and affective reactions to their whole life. They concern with the respondents' own internal judgment of well-being, rather than what policymakers, academics, or others consider important (Kau Ah Keng et al., 2002). The subjective well-being comprises of three interconnected elements namely life satisfaction, pleasant and unpleasant affects. These affect besides satisfaction represent people's evaluations of their lives and circumstances. The strong point of subjective well-being indicators is easier to modify in researches than objective ones, which are usually collected from government resources. Moreover, by measuring peoples' well-being on a common dimension, SWB measures can easily be compared across other domains than can objective measures usually involve different units of measurement (e.g., degree of pollution, calories, and income) (Diener \& Suh, 1997).

In summary, a handful of researchers argued strongly that, the quality of any entity has a subjective dimension that is perceptual as well as having an objective reality. This statement acknowledges that, both objective and subjective components of QOL are necessary to provide an understanding of it (Marans, 2012). But, in the choice of these two measurement indicators, research goals play an important role. Hence, this research aims to evaluate residents' quality of life through their subjective well being which is closely related to the ways residents perceive or evaluate their neighborhood condition to achieve life satisfaction.

\subsection{Urban Quality of Life and Neighborhood Satisfaction}

Recently, there has been an increase of interest in the field of quality of life (QOL) studies. The International Society for Quality of Life Studies (ISQOLS) is one of the good examples of this interest. The main goal of ISQOLS is assisting decision makers to apply performance measures and assessment techniques based on concepts such as well-being, human satisfaction, human development, happiness, and quality of life (Marans, 2012). Consequently, quality of life involves enormous researches in the various fields such as education, medical, social sciences, and families. In addition, it appears in the discussion of livability of cities to impact on social and economic policies (Keles, 2012).

Since 1960's, the notion of quality of life emerged in public life and social sciences. Subsequently, it appeared as a focus of geographic inquiry in the 1970s, when researchers increasingly sought to understand the social and economic problems arising from inequities in access to both social and material resources (Hikmat et al., 2009). Further into the 1980s, the perception and experiences of QOL were becoming imperative in studies focusing the quality of a place or the geographic setting at various scales (country, city, community and neighborhood). These kinds of studies referred to the quality of urban life (QOUL) which 
dealt mainly with assisting urban policy development and leading resources to urban needs (Marans, 2012). This focus is conceptually distinct from individual QOL research that has examined factors impacting individual's well-being. Thus, the quality of life divided into two distinct concepts that are individual QOL, including family life, friends, partner satisfaction and environmental QOL, involving the quality of urban life as a term of particular interest to designers and environment behaviour researchers. The second group ranged in scale from the individual dwelling, community, neighborhood, city, region, or even to the state or nation. It has been documented that where people live, will influence their lives and therefore, their overall QOL (Marans \& Stimson, 2011).

Neighborhood quality to a certain extent determines residents' quality of life. Satisfaction with social and physical features of the neighborhood tends to contribute to the overall neighborhood satisfaction which influences positively the overall feelings toward life, i.e. quality of life (Salleh, 2012). On the other hand, neighborhood satisfaction measures the difference between residents' actual and desired neighborhood's circumstances. In fact, residents usually make their judgments about neighborhood conditions based on their needs and aspirations (Sirgy \& Cornwell, 2002).

The other theme, expressed in the literature on quality of life, is called the issue of causality. Both environmental quality and quality of life refer to the person, the environment and the relationship between them. This relationship is not a static one but a transaction process which makes it harder to define causality. In this case, three approaches are distinguished: 1) the economical approach, 2) the sociological approach, and 3) the psychological or subjective approach. Each of these deals differently with the aspect of causality. In the economic approach, well-being refereed to the economic developments. The sociological approach described by Veenhoven $(1995,1996,1999)$ based on the concept of happiness and the Happy Life Expectancy (HLE) index. Finally, in the psychological (subjective) approach, residents' perception about their neighborhood gauged through stated and revealed preference. The stated preferences ask people directly about their neighborhood preference but the revealed preferences examine how people actually live (Kamp et al., 2003).

\section{Materials and Methods}

In this study, subjective indicators measurement of QOL utilized to gauge individuals' attitudes, perceptions and levels of satisfaction in their neighborhood.

The current study conducted in a high density, mixed use neighborhood located in Kuala Lumpur Central area (city center). The city center district is one of the six strategic zones in the Kuala Lumpur metropolitan area of Malaysia with 1,813 hectares. It is the center of focus in Kuala Lumpur Structure Plan 2020 (KLSP 2020) in terms of residential, commercial, industrial, entertainment, educational functions, and a good public transport network. A neighborhood that accommodates middle to high income families in varied houses- two storey single family houses up to six storey apartments, selected as the study area. This neighborhood is bounded by the important streets of city center such as, Jalan Tun Abdul Razak, Jalan Semarak, and Jalan Perumahan Gurney. As a result, various public and private facilities, including Kuala Lumpur City Center Park, open spaces, local and commercial 
streets, public sport facilities, and public rail transit facilities, are accessible to its residents. Furthermore, this neighborhood is mostly occupied by students because of the proximity to the educational services, specifically the international campus of a public university in Malaysia (Universiti Teknologi Malaysia).

For the purpose of this study, a sample population of 100 households resident in the urban neighborhood selected using convenience sampling. The data gathered through a self administrated questionnaire and conducted in February 2010. The questionnaire consisted of three main sections. Through the first section, personal characteristics and socioeconomic variables of the respondents including age, gender, race, education, occupation status, and the duration of residency in their current neighborhood recorded. Second section comprised of thirteen items for measuring residents' satisfaction, based on six factors namely social life, good condition for children, safety, greenery and quietness, transport and community facilities and services such as shopping centers, leisure facilities, schools, universities, and workplaces. The participants rated at four-graded scale including, 1 (very dissatisfied), 2 (dissatisfied), 3 (satisfied), to 4 (very satisfied). Finally, in relation to the subjective indicators, respondents were asked to rate their overall quality of life on a six-point Likert scale ('As good as can be' to 'As bad as can be'). Data was analyzed using descriptive statistics, by generating frequencies and percentages of respondents' characteristics and mean scores of satisfaction.

\section{Results and Discussions}

The findings of this study resulted from the questionnaire survey based on the physical and social qualities of the selected neighborhood in order to evaluate residents' satisfaction. The first part of the findings consisted of results description of respondents' background. This was followed by the second part, which comprised of respondents' choices about their neighborhood location based on revealed preference method as well as their overall neighborhood satisfaction. The third part discussed the respondents' stated preference, which provided the researcher the knowledge and useful pointers in the furtherance of the QOL initiative. In conclusion, residents' satisfaction with the overall quality of life is represented.

\subsection{Background of Respondents}

Of the total one hundred respondents in this study, young people- belonging to the 18-24 age group, constituted the majority of respondents (43\%) but a few numbers belonged to elderly people (3\%). $37 \%$ of the respondents were male and $63 \%$ were female. According to racial backgrounds, other races (considered themselves not Malay, Indian and Chinese) clearly dominated the number of respondents in the survey with 57\%. Most (93\%) respondents had university education and only $7 \%$ had less than a high school education. A substantial proportion of respondents were students (57\%), nine respondents had governmental occupation, $11.5 \%$ worked in the private sector, $7 \%$ were housewife and notably, the least respondents group was unemployed and retired in $2.8 \%$. It can be summarized that $70 \%$ of respondents had been living in their neighborhood less than 3 years as a temporary residents, while $4 \%$ of respondents were permanent residents. 


\subsection{Respondents' Revealed Preferences}

This section discussed the respondents' choice about their neighborhood location based on the revealed preference method of psychological approach in the environmental quality of life.

Residents' choice about their neighborhood location is influenced by many factors including socioeconomic characteristics, life cycle, location of work and other major activities such as schools, shopping, family and friend. With respect to the respondent's occupation background (students, government servants and housewives), proximity to the facilities such as shopping services, public transport services, educational services and workplace opted as the significant factors for choosing a neighborhood location. This is because the ease of access to these facilities reduced respondents' time and financial costs. Hence, factors including good accessibility to public transport and services (32\%), employment (16\%) and financial reason (14\%) were highly preferred for selecting a neighborhood location by respondents. In fact, these are the reasons why most people prefer to live in city centers. The use of public facilities can be linked to accessibility and reduced the time and financial costs of access. Hammond (2005) in a self-administered survey in Century Wharf of Cardiff- a compact, and mid-size provincial city in the UK discovered that living in the city center, which is linked with workplace proximity and lower levels of car use have an influence on residents' neighborhood location choice. Therefore, neighborhood proximity to facilities and services can be suggested as a contributing factor to residents' well-being.

\subsection{Overall Satisfaction with Neighborhood}

In this section, satisfaction with the neighborhood determined through the judgment of respondents based on physical and social attributes of the neighborhood. Totally, six main factors including social life, better conditions for children, safety, greenery and quietness, transport, and community facilities and services were asked. The participants rated their satisfaction on four-graded scale from very dissatisfied to very satisfied.

The highest levels of residents' satisfaction signified in terms of neighborhood physical characteristics including access to public transport services, educational services, availability of good condition for children, housing quality, greenery and quietness and proximity to workplaces (mean scores of 3.20-3.03). They coincided with respondents' choices about their neighborhood location. This ratio was increased based on respondent's occupation. Most residents who were students $(87.5 \%)$, government servants $(77 \%)$ and housewives $(80 \%)$ expressed their satisfaction with neighborhood more than others. While, the respondents uttered being dissatisfied with security and safety in their neighborhood (mean scores of 2.58). (Refer to Table 2)

Certainly, most empirical studies found that neighborhood location is one of the important factors that affect neighborhood satisfaction. For that reason, the factors mentioned above motivated residents to live in the central area of Kuala Lumpur. The proximity of the neighborhood location to the educational services such as a public university (University of Technology Malaysia), to the public rail transit services and other city center facilities provided opportunities for the residents especially students and government servants to live in 


\section{Macrothink

this neighborhood.

Table 2. Satisfaction with Neighborhood Characteristics

\begin{tabular}{ll}
\hline Neighborhood Characteristics & $\begin{array}{l}\text { Level of Satisfaction (Mean } \\
\text { Score) }\end{array}$ \\
\hline Housing quality & 3.08 \\
Greenery and quietness & 3.03 \\
Good condition for children & 3.10 \\
Educational services & 3.12 \\
Shopping services & 2.97 \\
Public and private facilities & 2.90 \\
Proximity to workplace & 3.04 \\
Public transport services & 3.20 \\
Recreational facilities & 2.70 \\
Health services & 2.93 \\
Safety and security & 2.58 \\
Social contact with neighbours & 2.77 \\
Little social cohesion in neighborhood & 2.68 \\
\hline
\end{tabular}

\subsection{Respondents' Stated Preferences}

Stated preference is another method of psychological approach in the environmental quality of life. This section discussed this method by asking respondents about their ideal neighborhood quality preferences that were important in their choice of neighborhood environment. Therefore, respondents were asked to list the six most important neighborhood attributes, placed them in priority order and rated them on a 6-point Likert rating scale from very important to not at all. The most important neighborhood attributes consisted of social life, safety, good condition for children, transport services, greenery and quietness and proximity to public and private service.

As revealed in figure 1, safety was acknowledged as an important factor by the majority of respondents for choosing their ideal neighborhood. This was closely followed by the second most important preference; access to transport services. Finally, social life made up a minority of respondents' preferences. It means that, for a few numbers of respondents, particularly temporary residents, was imperative to have social contact with their neighbors, families or friends. 


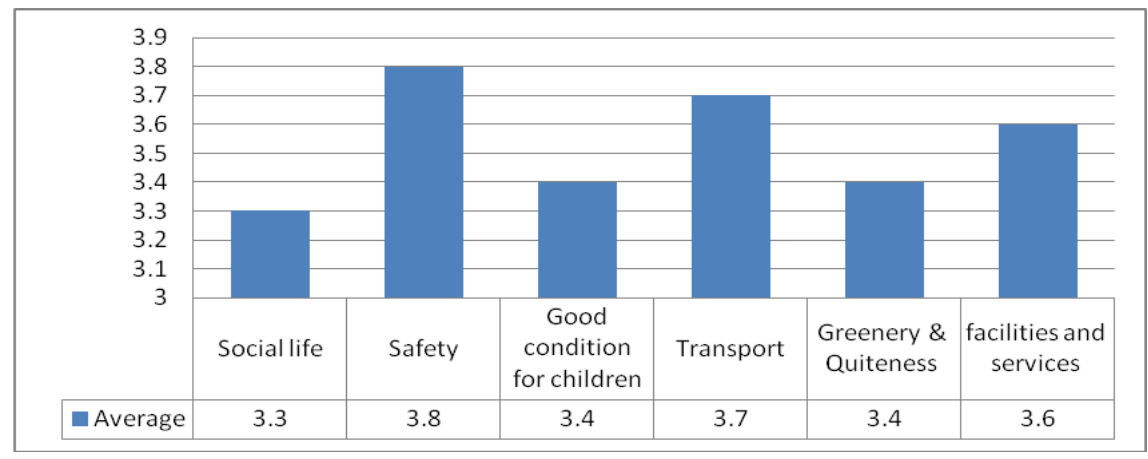

Figure 1. The respondents' ideal neighborhood quality preferences

\subsection{Satisfaction with Overall Quality of Life}

Finally, respondents were asked to rate their quality of life on a six-point Likert rating scale from as good as can be to as bad as can be. More than two-third of the respondents $(68 \%)$ satisfied with the overall quality of life, while the rest (32\%) expressed their feelings otherwise. They stated their satisfaction with the physical qualities of the neighborhood, i.e. access to public services, leisure and recreational facilities, educational services and public transport services. Although, little social cohesion in neighborhood and temporary residency, declared as the main factors to be less satisfied with the social conditions in the neighborhood.

In other words, respondents who were students, government sectors and housewives rated their overall quality of life high in the selected neighborhood similarly permanent and local residents such as Chinese, Indians and Malays as having more sense of attachment to their neighborhood than others. Fewness of those who were non-local and temporary residents, were more likely to rate their lives lower than the other group.

\section{Conclusion}

To achieve the stated aim, this study evaluated neighborhood physical and social attributes that contribute to residents' satisfaction in the central area of Kuala Lumpur. In summary, as the residents declared their satisfaction to the neighborhood physical features including proximity to the public transport services, educational services, workplaces, and public facilities, the overall residents' quality of life in studied central neighbourhood rated high. Therefore, understanding residents' needs through quality of life measurement would make certain that the planned urban areas are compatible with environmental quality criteria.

It is hoped that the findings of this study could be useful in the future formulation of planning and policies in Kuala Lumpur city center as one of the visions of Kuala Lumpur Structure Plan 2020 is creating a complete living environment in the inner city that provides the very best business and working environment together with a vibrant commercial, financial and entertainment centers. Moreover, this study has an implication for policy makers and planners to construct and develop sustainable neighborhoods through residents' own assessment of their local condition-especially in developing countries, like Malaysia. They can refer to its outcomes to enhance the social and physical features, which contribute to residents' quality of 
life and support their needs.

\section{Acknowledgement}

This paper is financially support by the "Center for The Study of Built Environment in the Malay World" (KALAM) and International Doctoral Fellowship (IDF) provided by Universiti Teknologi Malaysia and Ministry of Higher Education of Malaysia. The authors are very grateful to Prof. Dr. Mahbob Bin Salim, for his generous guidance in this research.

\section{References}

Andrews, F. M., \& Withey, S. (1976). Social indicators of well-being: Americans'perceptions of life quality. New York: Plenum Press.

Campbell, A., Converse, E., \& Rodgers, W. J. (1976). The quality of American life: Perceptions, evaluations, and satisfaction. (1st Ed.) New York, NY: Russell Sage Foundation.

Costanza, R., Fisher, B., \& Boumans, R. (2008). An integrative approach to quality of life measurement, research, and policy, the Institut Veolia Environnement, 1, 11-15. [Online] Available: www.surv-perspect-integr-envir-soc.net/1/11/2008/

Diener, E., \& Suh, E. (1997). Measuring quality of life: economic, social and subjective indicators, Social Indicators Research, 40, 189-216.

http://dx.doi.org/10.1023/a:1006859511756

Evans, D. (1994). Enhancing quality of Life in the population at large, Social Indicators Research series, 33, 47-88. http://dx.doi.org/ 10.1007/BF01078958

Hikmat, A., Malkawi, F., \& Al-Betawi, Y. (2009). Quality of Life in Cities: Setting up Criteria for Amman-Jordan, Social Indicators Research series, 93, 407-432.

http://dx.doi.org/10.1007/s11205-008-9333-5

Kamp, I., Leidelmeijer, K., Marsman, G., \& Hollander, A. (2003). Urban environmental quality and human well-being towards a conceptual framework and demarcation of concepts; a literature study, Landscape and Urban Planning, 65, 5-18.

http://dx.doi.org/10.1016/S0169-2046(02)00232-3

Kau Ah Keng, Swinyard, W., \& Phua Hui Yin. (2002). Quality of life in Singapore: an analysis of the influence of materialism and religiosity, Asia Pacific Advances in Consumer Research, 5, 282-283.

Keles, R. (2012). The Quality of Life and the Environment. Procedia-Social and Behavioral Sciences, 35, 23-32. http://dx.doi.org/ 10.1016/j.sbspro.2012.02.059

Marans, R. W., \& Stimson, R. J. (Eds.) (2011) Investigating Quality of urban life: Theory, method, and empirical research. Dordrecht, the Netherlands: Springer Publishing. 


\section{Macrothink}

Environmental Management and Sustainable Development

ISSN 2164-7682

2013, Vol. 2, No. 1

Marans, R. W. (2012). Quality of Urban Life Studies: An Overview and Implications for Environment-Behavior Research. Procedia-Social and Behavioral Sciences, 35, 9-22. http://dx.doi.org/10.1016/j.sbspro.2012.02.058

Omar, D. B. (2009). Assessing Residents' Quality of Life in Malaysian New Towns. Asian Social Science, 5(6), 94. http://www.ccsenet.org/journal/index.php/ass/article/view/2482/2329

Potter, J., Cantarero, R., \& Wood, H. (2012). The Multi-Dimensional Nature of Predicting Quality of Life. Procedia-Social and Behavioral Sciences, 50, 781-790.

http://dx.doi.org/10.1016/j.sbspro.2012.08.080

Salleh, A. (2012). Sustainable Urban Neighborhoods: The Need to Consider Residents' Satisfaction. OIDA International Journal of Sustainable Development, 3(10), 103-108. [Online] Available: http://www.ssrn.com/link/OIDA-Intl-Journal-Sustainable-Dev.html

Sirgy, M. J., \& Cornwell, T. (2002). How neighborhood features affect quality of life. Social Indicators Research, 59(1), 79-114. http://dx.doi.org/ 10.1023/A:1016021108513

Sirgy, J., Rahtz, D., Cicic, M., \& Underwood, R. (2000). A method for assessing resident's satisfaction with community-based services: a quality-of-life perspective, Social Indicators Research, 49, 279-316. http://dx.doi.org/ 10.1023/A:1006990718673

Windsor, J., \& Bowling, A. (2001). Towards the good life: A population survey of dimensions of quality of life, Journal of Happiness Studies, 2, 55-81.

http://dx.doi.org/10.1023/A:1011564713657

Zainal, N. R., Kaur, G., Ahmad, N. A., \& Khalili, J. M. (2012). Housing Conditions and Quality of Life of the Urban Poor in Malaysia. Procedia-Social and Behavioral Sciences, 50, 827-838. http://dx.doi.org/10.1016/j.sbspro.2012.08.085

Zebardast, E. (2009). The Housing Domain of Quality of Life and Life Satisfaction in the Spontaneous Settlements on the Tehran Metropolitan Fringe, Social Indicators Research series, 9, 307-324. http://dx.doi.org/10.1007/s11205-008-9260-5

\section{Copyright Disclaimer}

Copyright reserved by the author(s).

This article is an open-access article distributed under the terms and conditions of the Creative Commons Attribution license (http://creativecommons.org/licenses/by/3.0/). 